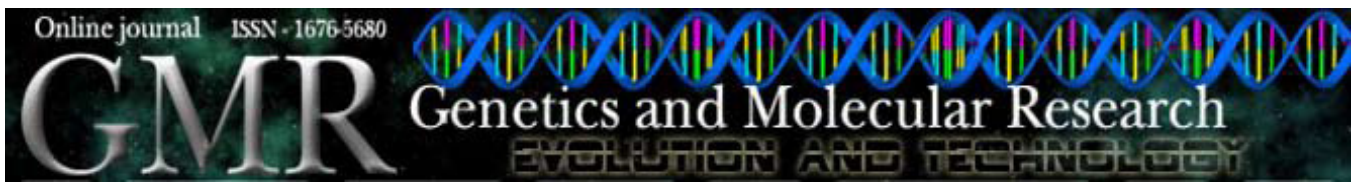

\title{
Germline HVR-II mitochondrial polymorphisms associated with breast cancer in Tunisian women
}

\author{
B. Yacoubi Loueslati ${ }^{1}$, W. Troudi ${ }^{2}$, L. Cherni ${ }^{2}$, K.B. Rhomdhane ${ }^{3}$ and \\ L. Mota-Vieira ${ }^{4,5}$ \\ ${ }^{1}$ Department of Biology, Faculty of Sciences of Tunis, ElManar University, \\ Tunis, Tunisia \\ ${ }^{2}$ Laboratory of Genetics, Immunology and Human Pathology, \\ Faculty of Sciences of Tunis, ElManar University, Tunisia \\ ${ }^{3}$ Salah Azeiz Oncology Institute, Bab Saadoun, Tunisia \\ ${ }^{4}$ Unidade de Genética e Patologia Moleculares, \\ Hospital do Divino Espírito Santo de Ponta Delgada, Ilha de São Miguel, \\ Azores, Portugal \\ ${ }^{5}$ Instituto Gulbenkian de Ciência, Oeiras, Portugal \\ Corresponding author: B. Yacoubi Loueslati \\ E-mail: BYacoubi.Loueslati@fst.rnu.tn
}

Genet. Mol. Res. 9 (3): 1690-1700 (2010)

Received March 19, 2010

Accepted May 15, 2010

Published August 31, 2010

DOI 10.4238/vol9-3gmr778

\begin{abstract}
A high incidence of somatic mtDNA polymorphisms has been reported in a wide variety of human cancers; some of them have been proposed as markers for the early detection of breast cancer. However, little attention has been paid to the potential of germline mitochondrial sequence variations as genetic risk factors for cancer. We performed a case-control study of 70 unrelated Tunisian women with breast cancer and 80 healthy age- and gender-matched blood donors, taking into account clinicopathological data, to evaluate germline polymorphism of mitochondrial HVR-II region as a genetic risk factor for breast cancer. Through direct sequencing, we detected 351 polymorphisms in controls and 248 variants in patients, with 47 and 39 segregating sites, respectively. In both groups, more than $50 \%$ of the polymorphisms were due to four variants: 315 ins $C, 309$ ins $C, 263 \mathrm{~A}>\mathrm{G}$, and $73 \mathrm{~A}>\mathrm{G}$. The
\end{abstract}


HVR-II sequences were also classified into haplotypes on the basis of the polymorphisms. Fifty-nine different haplotypes were found, 20 of them shared between patients and controls. Both groups had specific haplotypes, 18 in breast cancer patients and 21 in controls. Statistical analysis revealed a weak protective effect against breast cancer risk for two mitochondrial polymorphisms $-152 \mathrm{~T}>\mathrm{C}$ (odds ratio $(\mathrm{OR})=$ $0.33,95 \%$ confidence interval $(\mathrm{CI})=0.12-0.91)$ and $263 \mathrm{~A}>\mathrm{G}(\mathrm{OR}$ $=0.17,95 \% \mathrm{CI}=0.06-0.47)$. In contrast, an increased risk of breast cancer was detected for the $315+\mathrm{C}$ haplotype $(\mathrm{OR}=11.66,95 \% \mathrm{CI}$ $=1.44-252.23)$. We conclude that mitochondrial variants can affect breast cancer risk. More extensive studies, involving different types of cancer and patients with different genetic makeup, will be required to improve our understanding of the effects of germline mtDNA polymorphisms on carcinogenesis.

Key words: Breast cancer; mtDNA; Polymorphism; D-loop

\section{INTRODUCTION}

It is well established that mitochondria play a central role in cellular metabolism, since they fulfill the energy needs and are essential in the processing of metabolic intermediates for various pathways, including the metabolism of carbohydrates, amino acids and fatty acids (Chan, 2006; Wallace, 2007). These organelles are also vital for cell survival due to their involvement in several processes, including the production of reactive oxygen species (ROS), DNA damage and repair, cell cycle control, and regulation of cell death pathways, such as apoptosis, a fundamental biological process by which cells die in a well-programmed manner. Because apoptosis plays a critical role in cancer development and in cellular response to anticancer agents, the significance of mitochondrial DNA (mtDNA) mutations in cancer is obviously an important area of some current investigations (Wang, 2001; Higuchi, 2007; Asari et al., 2007; Lee and Wei, 2009).

Several studies have identified mutations in the non-coding and coding regions of mtDNA and have investigated their potential use as somatic markers for early tumor detection (Carew and Huang, 2002; Miyazono et al., 2002; Parrella et al., 2003; Zhou et al., 2007). For example, the integrity of the mitochondrial genome has been examined in 19 sets of paired normal and tumor tissues from the same patients with breast cancer (BC). In this case, the somatic polymorphisms (present only in tumor cells, and not affecting germline ones) were identified in $74 \%$ of the patients, and $81.5 \%$ of the variants were limited to the regulatory D-loop region (Tan et al., 2002). In two other studies, the investigators analyzed fine needle aspirates of primary breast tumors (Parrella et al., 2001; Zhu et al., 2005). In the majority of patients, the most frequently identified polymorphisms were also in the D-loop region. Among these variants, a mononucleotide repeat from nucleotide 303 to 315 (CCCCCCCTCCCCC) was revealed as a hot spot for deletions or insertions in breast tumors. Located in the second hypervariable region (HVR-II), this homopolymeric C-stretch is involved in the formation of a persistent RNA-DNA hybrid that leads to the initiation of mtDNA heavy-strand replication (Kang et al., 1997). 
Until now, little attention has been paid to the potential use of germline mitochondrial sequence variations (present in all cells) as a genetic risk factor for BC. To test this hypothesis, we evaluated, in a case-control study, the occurrence of HVR-II mitochondrial polymorphisms in Tunisian women with breast cancer and ethnically matched controls adjusted for gender and age, taking into account clinicopathological data.

\section{SUBJECTS AND METHODS}

\section{Study population}

Seventy unrelated women affected with BC (from 31 to 72 years) undergoing treatment in Salah Azeiz Oncology Institute (ISA, Tunisia) agreed to participate in the present study, which was approved by the local Ethics Committee. Twenty-four of them were already assessed in a previous study, which described two coding mutations - c.5266dupC and c.2551delG - in two unrelated BC cases (Troudi et al., 2008). The remaining 46 women were new patients identified during oncology and/or genetic consultations. Standardized written form of informed consent was obtained from all patients, before any procedure related to the study was performed. The control group consisted of eighty healthy female blood donors (from 30 to 70 years) matched for age, taking into account their menopausal status. Patients and controls are all Arabs, the major ethnic group of the Tunisian population. This selection minimizes bias since all participants have the same ethnic background, i.e., they share the same geographic origin, native language, and religion for at least three or four generations back. Blood samples were collected from all patients prior to radiation therapy or chemotherapy.

For all patients, cancer diagnosis was established by clinical examination, radiological findings and/or biopsy confirmed by two senior pathologists of the ISA. Clinicopathological data are summarized in Table 1, which includes the following variables: i) age at diagnosis; ii) menopausal status, defined by the permanent cessation of ovarian function; iii) histological subtype; iv) histological grade, assessed by Scarff-Bloom-Richardson (SBR) grading, which evaluates three morphologic features of BC (degree of tumor tubule formation, tumor mitotic activity, and nuclear pleomorphism of tumor cells); v) lymph node status, which serves as an indicator of the tumor's ability to spread, is positive or negative if cancer cells are present (increased risk of breast cancer metastasis) or absent (clear of cancer cells) in lymph nodes, respectively; vi) tumor node metastasis (TNM) staging, according to the American Joint Committee on Cancer (AJCC); vii) estrogen receptor (ER) status; viii) progesterone receptor (PR) status, and ix) BRCA1 mutation. Expression of ER and PR was determined by immunohistochemistry.

\section{DNA extraction and genotyping}

For each sample, mononuclear cells were isolated from $2 \mathrm{~mL}$ peripheral blood containing 0.1 M EDTA-K $\mathrm{K}_{3}$. Lysis of red blood cells was performed by two or three washings, using bidistilled water followed by centrifugation at $400 \mathrm{rpm}$ for $10 \mathrm{~min}$. Total DNA was extracted by proteinase $\mathrm{K}$ digestion from mononuclear cells and then column purified (QIAGEN Inc., Chatsworth, CA, USA).

The mitochondrial HVR-II region from nucleotide position (np) 57 to 372 (the complete DNA sequence of the human mitochondrial genome is available at www.ncbi.nlm.nih. 
gov/nuccore/251831106) was amplified by polymerase chain reaction (PCR) in a total reaction volume of $50 \mu \mathrm{L}$ containing $10 \mathrm{mM}$ Tris- $\mathrm{HCl}, \mathrm{pH} 8.3,50 \mathrm{mM} \mathrm{KCl}, 1.5-4.5 \mathrm{mM} \mathrm{MgCl}, 50$ mM dNTPs, $10 \mu \mathrm{M}$ of each primer (Forster et al., 1996) - L16340 (5'-AGCCATTTACCGTA CATAGCACA-3') and H408 (5'-TGTTAAAAGTGCATACCGCCA-3') - 10 ng genomic DNA and $2 \mathrm{U}$ Taq polymerase (Go Taq ${ }^{\circledR}$ Flexi DNA polymerase). The PCR cycling program comprised an initial denaturation at $95^{\circ} \mathrm{C}$ for $10 \mathrm{~min}$, followed by 35 cycles of $95^{\circ} \mathrm{C}$ for $10 \mathrm{~s}$, annealing of primers at $52^{\circ} \mathrm{C}$ for $30 \mathrm{~s}$ and extension at $72^{\circ} \mathrm{C}$ for $30 \mathrm{~s}$. The amplified products were purified with the Invitrogen PCR purification kit (K3 100-01).

The sequencing reaction was carried out using the Big Dye Terminator (version 3.0) Cycle sequencing kit, with ampliTaq ${ }^{\circledR}$ DNA polymerase (AB Applied Biosystems) and performed separately on each strand with the primers L16340 and H408. Sequences were run in an automatic sequencer ABIPRISM 377 (AB Applied Biosystems).

\section{Statistical analysis}

The mtDNA sequence analysis was carried out for nucleotide positions 64 to 340 . The sequences (cases and controls) were compared to the revised Cambridge Reference Sequence (rCRS; Andrews et al., 1999) and classified into haplotypes on the basis of the revealed segregating sites. The mtDNA haplotype frequencies were directly estimated by the following equation $[f=(n \mid N) \times 100]$, where " $n$ " is the number and " $N$ " is the total number of samples. The statistical analyses were performed using the Epi-Info 6 package program (www.ensp.fr/ services/logiciels/epiinfo_604d_fr.htm). Pearson chi-square or Fisher tests (when the number of subjects in a cell is $<\overline{5}$ ) were performed on $2 \times 2$ contingency tables. The difference was considered to be statistically significant when $\mathrm{P}<0.05$. The odds ratio (OR) with $95 \%$ confidence interval (CI) was also determined.

\section{RESULTS}

Table 1 lists the observed clinicopathological characteristics of 70 Tunisian women with $\mathrm{BC}$. The median age at diagnosis was 48 years, ranging from 31 to 72 . Thirty-two patients were premenopausal and 38 were postmenopausal. Two histological types were identified: infiltrative ductal carcinoma (63/70 cases, 90\%) and lobular ductal carcinoma (6/70 cases, $8.6 \%)$. One patient had a breast tumor with mixed histological pattern of both types (infiltrative ductal carcinoma and lobular ductal carcinoma). Modified SBR histological grade was determined for all patients: $5(7.1 \%)$ were grade I, $35(50 \%)$ were grade II, and $30(42.8 \%)$ were grade III. Lymph nodes were positive for $54(64.2 \%)$ patients, and negative for $16(35.7 \%)$ patients. The distribution of breast cancer staging at diagnosis was 5 cases $(7.1 \%)$ stage I, 45 cases $(64.3 \%)$ stage II, 10 cases (14.3\%) stage III, and 10 cases (14.3\%) stage IV, the metastatic breast cancer stage. Forty-five cases $(64.3 \%)$ had a positive ER status, and 25 (35.7\%) were negative; PR status was positive for 49 (70\%), and negative for $21(30.0 \%)$. Twenty-five cases were positive for the two receptors $(\mathrm{ER}+\mathrm{PR}+)$, and 16 were negative for both (ER-/PR-).

The comparison of each sequence of healthy individuals (80) and cases (70) to the rCRS (Andrews et al., 1999) shows a total of 351 polymorphisms for the healthy group and 248 variants for patients, each group having 47 and 39 segregating sites, respectively (data not 
shown, but available under request). All variants are known. In the two groups - patients and controls - the four most frequent polymorphisms are a C insertion at np 315 (23.3 and 20.2\%, respectively), a $\mathrm{C}$ insertion at np 309 (9.6 and 7.4\%, respectively), an $\mathrm{A}>\mathrm{G}$ transition at np 263 (19.3 and $21.0 \%$, respectively), and an $\mathrm{A}>\mathrm{G}$ transition at $\mathrm{np} 73$ (10.8 and $10.2 \%$, respectively). A relatively high instability of mitochondrial microsatellites, within the mononucleotide repeat, located between positions 303 and 315, was detected: 100 of the 248 (40.3\%) polymorphisms observed in patients, and 119 of the 351 (33.9\%) variants observed in controls (data not shown, but available under request).

\begin{tabular}{|c|c|c|}
\hline \multirow[t]{2}{*}{ Variable } & \multicolumn{2}{|c|}{ Patients } \\
\hline & $\overline{\mathrm{N}}$ & $\%$ \\
\hline \multicolumn{3}{|c|}{ Age at diagnosis (years) } \\
\hline $31-40$ & 10 & 14.2 \\
\hline $41-50$ & 20 & 28.5 \\
\hline $51-60$ & 32 & 45.7 \\
\hline $61-70$ & 7 & 10.0 \\
\hline$\geq 71$ & 1 & 1.4 \\
\hline \multicolumn{3}{|l|}{ Menopausal status } \\
\hline Premenopausal & 32 & 45.7 \\
\hline Postmenopausal & 38 & 54.3 \\
\hline \multicolumn{3}{|l|}{ Histological subtype } \\
\hline IDC & 63 & 90.0 \\
\hline $\mathrm{IDC}+\mathrm{LDC}$ & 1 & 1.4 \\
\hline LDC & 6 & 8.6 \\
\hline \multicolumn{3}{|l|}{ Histological grade } \\
\hline I & 5 & 7.1 \\
\hline II & 35 & 50.0 \\
\hline III & 30 & 42.8 \\
\hline \multicolumn{3}{|l|}{ Lymph node status } \\
\hline Negative & 16 & 35.7 \\
\hline Positive & 54 & 64.2 \\
\hline \multicolumn{3}{|l|}{ TNM staging } \\
\hline Stage I & 5 & 7.1 \\
\hline Stage IIA & 14 & 20.0 \\
\hline Stage IIB & 31 & 44.3 \\
\hline Stage IIIA & 4 & 5.7 \\
\hline Stage IIIB & 6 & 8.6 \\
\hline Stage IV & 10 & 14.3 \\
\hline \multicolumn{3}{|c|}{ Estrogen receptor status } \\
\hline Negative & 25 & 35.7 \\
\hline Positive & 45 & 64.3 \\
\hline \multicolumn{3}{|c|}{ Progesterone receptor status } \\
\hline Negative & 21 & 30.0 \\
\hline Positive & 49 & 70.0 \\
\hline \multicolumn{3}{|l|}{ BRCA1 mutation* } \\
\hline c. $2551 \mathrm{delG}$ & 1 & 4.2 \\
\hline c.5266dupC & 1 & 4.2 \\
\hline
\end{tabular}

The mtDNA HVR-II sequences were also classified into haplotypes, on the basis of the polymorphisms revealed after alignment of each sequence from np 64 to $n p 340$ against the rCRS (Table 2). A total of 59 different haplotypes were found in the present study, the majority of them (19 in patients and 24 in controls) were detected only in one individual. However, 20 haplotypes were shared between $\mathrm{BC}$ patients and controls. Both groups had specific haplotypes (18 in cases, and 21 in controls). 
Table 2. Mitochondrial DNA HVR-II haplotypes identified in Tunisian female breast cancer patients and controls.

\begin{tabular}{|c|c|c|c|c|}
\hline \multirow[t]{2}{*}{ Haplotypes } & \multicolumn{2}{|c|}{ Patients (70) } & \multicolumn{2}{|c|}{ Controls (80) } \\
\hline & $\mathrm{N}$ & $\%$ & $\overline{\mathrm{N}}$ & $\%$ \\
\hline rCRS & 1 & 1.43 & 2 & 2.50 \\
\hline $263309+\mathrm{C} 315+\mathrm{C}$ & 3 & 4.30 & 4 & 5.00 \\
\hline $263309+\mathrm{CC} 315+\mathrm{C}$ & 2 & 2.85 & 3 & 3.75 \\
\hline $073263315+\mathrm{C}$ & 2 & 2.85 & 5 & 6.25 \\
\hline $315+\mathrm{C}$ & 9 & 12.85 & 1 & 1.25 \\
\hline $263315+\mathrm{C}$ & 4 & 5.71 & 9 & 11.25 \\
\hline $073263309+\mathrm{C} 315+\mathrm{C}$ & 2 & 2.85 & 1 & 1.25 \\
\hline $195263309+\mathrm{C} 315+\mathrm{C}$ & 1 & 1.43 & 2 & 2.50 \\
\hline $263276309+\mathrm{C} 315+\mathrm{C}$ & 1 & 1.43 & 3 & 3.75 \\
\hline $263315+C 316$ & 1 & 1.43 & 1 & 1.25 \\
\hline $073198263315+A$ & 2 & 2.85 & 1 & 1.25 \\
\hline $083152161175 d 220245252263294315+C$ & 1 & 1.43 & 2 & 2.50 \\
\hline $073150152253263295309+\mathrm{C} 315+\mathrm{C}$ & 1 & 1.43 & 1 & 1.25 \\
\hline $073146152263309+\mathrm{C} 315+\mathrm{C}$ & 1 & 1.43 & 1 & 1.25 \\
\hline $073189263309+\mathrm{CC} 315+\mathrm{C}$ & 2 & 2.85 & 2 & 2.50 \\
\hline $073263309+\mathrm{CC}$ & 1 & 1.43 & 1 & 1.25 \\
\hline $072263315+\mathrm{C}$ & 1 & 1.43 & 1 & 1.25 \\
\hline $073309+\mathrm{CC} 315+\mathrm{C}$ & 2 & 2.85 & 1 & 1.25 \\
\hline $073263309+\mathrm{CC}$ & 2 & 2.85 & 1 & 1.25 \\
\hline $152195263309+\mathrm{CC} 315+\mathrm{C}$ & 1 & 1.43 & 6 & 7.50 \\
\hline $073141146152195263309+\mathrm{C} 315+\mathrm{C}$ & - & - & 1 & 1.25 \\
\hline $285309+\mathrm{C} 315+\mathrm{C}$ & - & - & 1 & 1.25 \\
\hline 073185188198295 & - & - & 1 & 1.25 \\
\hline $073143146152195263315+\mathrm{C}$ & - & - & 2 & 2.50 \\
\hline $150263309+\mathrm{C} 315+\mathrm{C}$ & - & - & 1 & 1.25 \\
\hline $297315+A$ & - & - & 1 & 1.25 \\
\hline $073199204250263309+\mathrm{C} 315+\mathrm{C}$ & - & - & 1 & 1.25 \\
\hline $072263310 \mathrm{~d}$ & - & - & 1 & 1.25 \\
\hline $114132151195198253263309+\mathrm{C} 315+\mathrm{C}$ & - & - & 1 & 1.25 \\
\hline $132 \mathrm{C} / \mathrm{T} 263309+\mathrm{CC} 315+\mathrm{C}$ & - & - & 1 & 1.25 \\
\hline $253272297309+\mathrm{CC} 315+\mathrm{C}$ & - & - & 2 & 2.50 \\
\hline $073150263309+\mathrm{C} 315+\mathrm{C}$ & - & - & 2 & 2.50 \\
\hline $073152263315+\mathrm{C}$ & - & - & 3 & 3.75 \\
\hline $146263310 \mathrm{~d}$ & - & - & 1 & 1.25 \\
\hline $073111152195198257263309+\mathrm{CC} 315+\mathrm{C}$ & - & - & 1 & 1.25 \\
\hline $220263309+\mathrm{C} 315+\mathrm{C}$ & - & - & 3 & 3.75 \\
\hline $073090114125136141199204263315+\mathrm{C}$ & - & - & 1 & 1.25 \\
\hline $073189200263315+\mathrm{C}$ & - & - & 1 & 1.25 \\
\hline $073150188200263309+C 315+C$ & - & - & 1 & 1.25 \\
\hline $073146152183263279315+C$ & - & - & 3 & 3.75 \\
\hline $073151263309+\mathrm{C} 315+\mathrm{C}$ & - & - & 3 & 3.75 \\
\hline $073242263295315+C$ & 2 & 2.85 & - & - \\
\hline $309+\mathrm{C} 315+\mathrm{C}$ & 4 & 5.71 & - & - \\
\hline $293309+C 315+C$ & 2 & 2.85 & - & - \\
\hline $073185263309+\mathrm{C} 315+\mathrm{C}$ & 1 & 1.43 & - & - \\
\hline $073150263315+C$ & 1 & 1.43 & - & - \\
\hline $150207263309+\mathrm{C} 315+\mathrm{C}$ & 1 & 1.43 & - & - \\
\hline $073150195263295309+\mathrm{C}$ & 2 & 2.85 & - & - \\
\hline $073152199263309+\mathrm{C} 315+\mathrm{C}$ & 1 & 1.43 & - & - \\
\hline $073150305+\mathrm{A}$ & 2 & 2.85 & - & - \\
\hline $065114263309+\mathrm{C} 315+\mathrm{C}$ & 1 & 1.43 & - & - \\
\hline $198236263309+\mathrm{C} 315+\mathrm{C}$ & 1 & 1.43 & - & - \\
\hline $199241263295315+\mathrm{C}$ & 1 & 1.43 & - & - \\
\hline $073081198253263284309+\mathrm{C} 315+\mathrm{C}$ & 1 & 1.43 & - & - \\
\hline $073263315+\mathrm{A}$ & 2 & 2.85 & - & - \\
\hline $198263315+\mathrm{C}$ & 1 & 1.43 & - & - \\
\hline $081085198263309+\mathrm{C} 315+\mathrm{C}$ & 3 & 4.30 & - & - \\
\hline $152195315+\mathrm{C}$ & 2 & 2.85 & - & - \\
\hline $212232263309+\mathrm{C} 315+\mathrm{C}$ & 2 & 2.85 & - & - \\
\hline
\end{tabular}

rCRS = revised Cambridge Reference Sequence (Andrews et al., 1999). 
In order to test the germline mtDNA as a genetic risk factor for $\mathrm{BC}$, we compared the occurrence and evaluated the association of HVR-II mitochondrial polymorphisms or haplotypes in Tunisian BC women with ethnically matched controls, stratified by the clinical and pathological characteristics of BC. Overall, there was no significant association of histological subtype, grade, lymph node status, and TNM staging of BC, with either ER/PR status or the HVR-II polymorphisms or haplotypes detected (data not shown). However, two transitions ( $\mathrm{T}>\mathrm{C}$ at np 152 and $\mathrm{A}>\mathrm{G}$ at np 263) and one haplotype (315+C), with different effects, showed significant associations with breast cancer (Table 3 ). When we analyzed the two polymorphisms, we observed a weak protective effect against $\mathrm{BC}$ in the overall population $(152 \mathrm{~T}>\mathrm{C}$ : $\mathrm{OR}=0.33,95 \% \mathrm{CI}=0.12-0.91, \mathrm{P}=0.017$, and $263 \mathrm{~A}>\mathrm{G}: \mathrm{OR}=0.17,95 \% \mathrm{CI}=0.06-0.47, \mathrm{P}=$ 0.000 ), independent of their menopause status. In contrast, an increased risk for $\mathrm{BC}$ was detected for all women with the $315+\mathrm{C}$ haplotype $(\mathrm{OR}=11.66,95 \% \mathrm{CI}=1.44-252.23, \mathrm{P}=0.004$; Table 3). This haplotype was detected in nine BC women all with infiltrate ductal carcinoma, the dominant histological subtype observed.

\begin{tabular}{|c|c|c|c|}
\hline & \multicolumn{2}{|c|}{ Germinal polymorphisms } & \multirow{2}{*}{$\frac{\text { Germinal haplotype }}{315+\mathrm{C}}$} \\
\hline & $152 \mathrm{~T}>\mathrm{C}$ & $263 \mathrm{~A}>\mathrm{G}$ & \\
\hline \multicolumn{4}{|l|}{ Premenopausal } \\
\hline Patients $(\mathrm{N}=32)$ & 1 & 22 & 5 \\
\hline Controls $(\mathrm{N}=40)$ & 8 & 39 & 0 \\
\hline$P$ & 0.032 & 0.000 & 0.014 \\
\hline OR $(95 \% \mathrm{CI})$ & $0.13(0.01-1.13)$ & $0.06(0.00-0.48)$ & - \\
\hline \multicolumn{4}{|l|}{ Postmenopausal } \\
\hline Patients $(\mathrm{N}=38)$ & 6 & 25 & 4 \\
\hline Controls $(\mathrm{N}=40)$ & 12 & 35 & 1 \\
\hline $\mathrm{P}$ & $0.136^{\mathrm{NS}}$ & 0.022 & 0.036 \\
\hline OR $(95 \% \mathrm{CI})$ & $0.44(0.13-1.48)$ & $0.27(0.07-0.98)$ & $9.29(0.92-226.80)$ \\
\hline \multicolumn{4}{|l|}{ All } \\
\hline Patients $(\mathrm{N}=70)$ & 7 & 47 & 9 \\
\hline Controls $(\mathrm{N}=80)$ & 20 & 74 & 1 \\
\hline$P$ & 0.017 & 0.000 & 0.004 \\
\hline OR $(95 \% \mathrm{CI})$ & $0.33(0.12-0.91)$ & $0.17(0.06-0.47)$ & $11.66(1.44-252.23)$ \\
\hline
\end{tabular}

\section{DISCUSSION}

During the past decade, many mechanisms underlying tumor cell growth and survival have been proposed and studied. One of them concerns the mtDNA D-loop region, which acts as a promoter for heavy and light strands of the mitochondrial genome. Cleveland et al. (2006) proposed that nucleotide variations affecting the transcription of mitochondrial genes may cause mtDNA malfunction and contribute to a poorer prognosis in BC patients. Until now, few data exist regarding the correlation of germline mtDNA content with clinical and/or pathological characteristics of BC. Nevertheless, the published literature suggests that mtDNA may harbor potential biomarkers for early detection of BC (Parrella et al., 2003; Jakupciak et al., 2006; Modica-Napolitano et al., 2007). Here, we performed a case-control study in order to evaluate the germline HVR-II mitochondrial polymorphisms and haplotypes as risk factors for BC in Tunisian women, taking into account clinicopathological data.

Our results suggest that the mitochondrial genome has two polymorphisms $[152 \mathrm{~T}>\mathrm{C}$ 
$(\mathrm{OR}=0.33,95 \% \mathrm{CI}=0.12-0.91)$ and $263 \mathrm{~A}>\mathrm{G}(\mathrm{OR}=0.17,95 \% \mathrm{CI}=0.06-0.47)]$ with weak protective effect against $\mathrm{BC}$ risk at the germline level and independent of menopause status. $\mathrm{Yu}$ and collaborators (2008) also detected these two polymorphisms at the somatic level in $1 / 23(4.3 \%)$ and 23/23 (100\%) breast cancers, respectively. The high occurrence of the 263 polymorphism in tumor cells may be caused by the high production of ROS in neoplastic cells. In fact, it was reported that in addition to an inefficient DNA repair system, a gradual increase in ROS levels may cause mtDNA damage and mutations (Lee and Wei, 2005). However, the reasons why these two polymorphisms are protective at the germline level are still not understood, and further studies are required to confirm this protective effect against BC risk.

Several investigators have evaluated the relationship between mitochondrial or nuclear polymorphisms and $\mathrm{BC}$ in different populations; they reported that $\mathrm{BC}$ risk may be modified specially in premenopausal women. For example, the codon 432 polymorphism of the $C Y P 1 B 1$ gene is associated with an increased BC risk, particularly in premenopausal African women (Okobia et al., 2009). Moreover, genetic variants in the biotransformation enzyme CYP17 had no major effect on BC proneness in the overall population, but it modified the $\mathrm{BC}$ risk for certain subgroups of patients, particularly in premenopausal women (Antognelli et al., 2009). A modestly increased risk was only found in Nigerian premenopausal women with $\mathrm{BC}$ harboring an $\mathrm{A}$ to $\mathrm{G}$ transition in codon 223 of the leptin receptor gene (Okobia et al., 2008). Other studies have uncovered associations between some mitochondrial variants and $\mathrm{BC}$ risk. In fact, the mitochondrial 10398A allele conferred a significantly increased risk of BC in African-American women regardless of menopausal status (Canter et al., 2005). In the present study, the stratified analysis by menopausal status showed that the weak protective effect against $\mathrm{BC}$ risk of the $152 \mathrm{~T}>\mathrm{C}$ and $263 \mathrm{~A}>\mathrm{G}$ polymorphisms is not dependent on this physiological variable. Moreover, our results also displayed that mtDNA polymorphisms did not correlate with the other clinicopathological parameters, i.e., age at diagnosis, histological subtype, grade, lymph node status, and TNM staging. Similar results were obtained by Bragoszewski and collaborators (2008) in studies on ovarian cancer risk assessment. However, the significance of these results is still a subject of some controversy, since 1) low mtDNA content was identified in tumor specimens of BC at an early TNM stage (stage I) as compared with more advanced stages, suggesting that it may be essential in the early progression of BC (Xia et al., 2009), and 2) reduced mtDNA content shows a significant correlation with BC patient's ER or PR status (Yu et al., 2007). Therefore, the relationship between mtDNA content/ polymorphisms and clinicopathological characteristics of cancers remains unclear and needs further investigation, because they may influence the outcome of $\mathrm{BC}$ therapy, particularly endocrine treatments.

Regarding mitochondrial haplotype analysis based on polymorphic sites between nucleotide positions 64 to 340, we found that the risk for BC in Tunisian women is independent of their menopausal status, and seems to be only associated with the $315+\mathrm{C}$ haplotype (OR $=11.66,95 \% \mathrm{CI}=1.44-252.23)$. This association needs to be replicated in additional large case-control studies based on calculated sample size, in order to decrease the upper confidence interval and to improve the stratified matching, as well as in independent populations in order to generalize the results to any other cohort. Nevertheless, since all individuals analyzed have the same ethnic origin - all being Arab, the major ethnic group of the Tunisian population -, our population-based case-control study design has the advantage of minimizing the confounding effect that an unidentified population substructure could have. Here, the $315+\mathrm{C}$ 
haplotype was detected in nine $\mathrm{BC}$ women all with infiltrative ductal carcinoma. Since two of them also carry one BRCA1 mutation - c.2551delG or c.5266dupC (Troudi et al., 2008) - it is reasonable to hypothesize that the combined effect of these sequence variants could potentially contribute to the increased risk for $\mathrm{BC}$ in people with a family history of this malignancy. Indeed, it was recently reported that among three high-risk cancer families (for breast, lung, prostate, or colorectal cancer), individuals affected with $\mathrm{BC}$ harbored more mtDNA sequence variants between np 303 and 315 than other affected family members (Yu et al., 2008). The mechanism underlying the relationship between the $315+\mathrm{C}$ haplotype and $\mathrm{BC}$ predisposition remains to be elucidated. However, considering that the mononucleotide repeat from np 303 to 315 (CCCCCCCTCCCCC) is implicated in the initiation of the mtDNA heavy-strand replication; alterations of this sequence may change the rate of transcription and replication of the mitochondrial genome. Asari et al. (2007) have demonstrated that the 303-315 length variations generate quantitative and qualitative differences in prematurely terminated transcripts. Recently, Ye et al. (2008) reported that carrying multiple alleles (heteroplasmy) of the mtDNA D-loop (CA)n repeat polymorphism, in the third hypervariable region HVR-III may be associated with BC survival. We plan to study the sequence of the first hypervariable region (HVR-I) in $\mathrm{BC}$ patients, including the nine cases who have the $315+\mathrm{C}$ haplotype, in order to identify the related mtDNA haplogroups. In fact, it has been reported that the inheritance of mitochondrial halogroup $\mathrm{U}$ is associated with approximately 2 -fold increased risk for prostate cancer and 2.5-fold increased risk for renal cancer in white North America individuals (Booker et al., 2006), and that haplogroup D may be a genetic risk factor for endometrial cancer in southwest China (Xu et al., 2006).

The results obtained in the present case-control study must be considered with some caution, because we did not exclude BC women with gynecological or endocrine problems nor in a menopausal status using hormone replacement therapy, features that may represent a pitfall in patient selection. In addition, the patients participated on a voluntary basis, which may have produced a bias in the results, since women who submit spontaneously to screening may have a different perception of their health status as compared to the overall population.

Nevertheless, it is important to note that our results demonstrate a weak protective effect against breast cancer risk in Tunisian women harboring the mtDNA $152 \mathrm{~T}>\mathrm{C}$ or $263 \mathrm{~A}>\mathrm{G}$ germline polymorphisms, and a possible increased risk associated with the $315+\mathrm{C}$ haplotype, a hypothesis that should be tested with more samples. The present study also provides additional evidence that mtDNA polymorphisms and any resulting changes in mitochondrial function may modify the risk for $\mathrm{BC}$ and/or may play a role, with a variable degree of penetrance, in the etiology of this multifactorial disease. More extensive studies with different types of cancer and using patients with different genetic makeup should provide additional insights and improve our understanding of germline and/or somatic mtDNA variants in carcinogenesis. Finally, our analysis also contributes to the conclusion that molecular diagnostic tests based on mtDNA have, at this time, limited clinical relevance in $\mathrm{BC}$, and will require additional large well-designed validation studies before their use in clinical practice.

\section{ACKNOWLEDGMENTS}

Research partially supported by the Tunisian Ministry of Higher Education and Scien- 
tific Research. We thank all the women with breast cancer and healthy donors who agreed to help us conduct the present study and the staff of Salah Azeiz Oncology Institute for their help in the collection of blood samples.

\section{REFERENCES}

Andrews RM, Kubacka I, Chinnery PF, Lightowlers RN, et al. (1999). Reanalysis and revision of the Cambridge reference sequence for human mitochondrial DNA. Nat. Genet. 23: 147.

Antognelli C, Del Buono C, Ludovini V, Gori S, et al. (2009). CYP17, GSTP1, PON1 and GLO1 gene polymorphisms as risk factors for breast cancer: an Italian case-control study. BMC Cancer 9: 115.

Asari M, Tan Y, Watanabe S, Shimizu K, et al. (2007). Effect of length variations at nucleotide positions 303-315 in human mitochondrial DNA on transcription termination. Biochem. Biophys. Res. Commun. 361: 641-644.

Booker LM, Habermacher GM, Jessie BC, Sun QC, et al. (2006). North American white mitochondrial haplogroups in prostate and renal cancer. J. Urol. 175: 468-472.

Bragoszewski P, Kupryjanczyk J, Bartnik E, Rachinger A, et al. (2008). Limited clinical relevance of mitochondrial DNA mutation and gene expression analyses in ovarian cancer. BMC Cancer 8: 292.

Canter JA, Kallianpur AR, Parl FF and Millikan RC (2005). Mitochondrial DNA G10398A polymorphism and invasive breast cancer in African-American women. Cancer Res. 65: 8028-8033.

Carew JS and Huang P (2002). Mitochondrial defects in cancer. Mol. Cancer 1: 9.

Chan DC (2006). Mitochondria: dynamic organelles in disease, aging, and development. Cell 125: 1241-1252.

Cleveland RJ, Gammon MD, Edmiston SN, Teitelbaum SL, et al. (2006). IGF1 CA repeat polymorphisms, lifestyle factors and breast cancer risk in the Long Island Breast Cancer Study Project. Carcinogenesis 27: 758-765.

Forster P, Harding R, Torroni A and Bandelt HJ (1996). Origin and evolution of Native American mtDNA variation: a reappraisal. Am. J. Hum. Genet. 59: 935-945.

Higuchi M (2007). Regulation of mitochondrial DNA content and cancer. Mitochondrion 7: 53-57.

Jakupciak JP, Dakubo GD, Maragh S and Parr RL (2006). Analysis of potential cancer biomarkers in mitochondrial DNA. Curr. Opin. Mol. Ther. 8: 500-506.

Kang D, Miyako K, Kai Y, Irie T, et al. (1997). In vivo determination of replication origins of human mitochondrial DNA by ligation-mediated polymerase chain reaction. J. Biol. Chem. 272: 15275-15279.

Lee HC and Wei YH (2005). Mitochondrial biogenesis and mitochondrial DNA maintenance of mammalian cells under oxidative stress. Int. J. Biochem. Cell Biol. 37: 822-834.

Lee HC and Wei YH (2009). Mitochondrial DNA instability and metabolic shift in human cancers. Int. J. Mol. Sci. 10: 674-701.

Miyazono F, Schneider PM, Metzger R, Warnecke-Eberz U, et al. (2002). Mutations in the mitochondrial DNA D-Loop region occur frequently in adenocarcinoma in Barrett's esophagus. Oncogene 21: 3780-3783.

Modica-Napolitano JS, Kulawiec M and Singh KK (2007). Mitochondria and human cancer. Curr. Mol. Med. 7: 121-131.

Okobia MN, Bunker CH, Garte SJ, Zmuda JM, et al. (2008). Leptin receptor Gln223Arg polymorphism and breast cancer risk in Nigerian women: a case control study. BMC Cancer 8: 338.

Okobia MN, Bunker CH, Garte SJ, Zmuda JM, et al. (2009). Cytochrome P450 1B1 Val432Leu polymorphism and breast cancer risk in Nigerian women: a case control study. Infect. Agent. Cancer 4 (Suppl 1): S12.

Parrella P, Xiao Y, Fliss M, Sanchez-Cespedes M, et al. (2001). Detection of mitochondrial DNA mutations in primary breast cancer and fine-needle aspirates. Cancer Res. 61: 7623-7626.

Parrella P, Seripa D, Matera MG, Rabitti C, et al. (2003). Mutations of the D310 mitochondrial mononucleotide repeat in primary tumors and cytological specimens. Cancer Lett. 190: 73-77.

Tan DJ, Bai RK and Wong LJ (2002). Comprehensive scanning of somatic mitochondrial DNA mutations in breast cancer. Cancer Res. 62: 972-976.

Troudi W, Uhrhammer N, Romdhane KB, Sibille C, et al. (2008). Complete mutation screening and haplotype characterization of BRCA1 gene in Tunisian patients with familial breast cancer. Cancer Biomark. 4: 11-18.

Wallace DC (2007). Why do we still have a maternally inherited mitochondrial DNA? Insights from evolutionary medicine. Аnпи. Rev. Biochem. 76: 781-821.

Wang X (2001). The expanding role of mitochondria in apoptosis. Genes Dev. 15: 2922-2933.

Xia P, An HX, Dang CX, Radpour R, et al. (2009). Decreased mitochondrial DNA content in blood samples of patients with stage I breast cancer. BMC Cancer 9: 454.

$\mathrm{Xu} \mathrm{L}, \mathrm{Hu} \mathrm{Y}$, Chen B, Tang W, et al. (2006). Mitochondrial polymorphisms as risk factors for endometrial cancer in 
southwest China. Int. J. Gynecol. Cancer 16: 1661-1667.

Ye C, Gao YT, Wen W, Breyer JP, et al. (2008). Association of mitochondrial DNA displacement loop (CA)n dinucleotide repeat polymorphism with breast cancer risk and survival among Chinese women. Cancer Epidemiol. Biomarkers Prev. 17: 2117-2122.

Yu M, Zhou Y, Shi Y, Ning L, et al. (2007). Reduced mitochondrial DNA copy number is correlated with tumor progression and prognosis in Chinese breast cancer patients. IUBMB Life 59: 450-457.

Yu M, Shi Y, Zhang F, Zhou Y, et al. (2008). Sequence variations of mitochondrial DNA D-loop region are highly frequent events in familial breast cancer. J. Biomed. Sci. 15: 535-543.

Zhou S, Kachhap S, Sun W, Wu G, et al. (2007). Frequency and phenotypic implications of mitochondrial DNA mutations in human squamous cell cancers of the head and neck. Proc. Natl. Acad. Sci U. S. A. 104: 7540-7545.

Zhu W, Qin W, Bradley P, Wessel A, et al. (2005). Mitochondrial DNA mutations in breast cancer tissue and in matched nipple aspirate fluid. Carcinogenesis 26: 145-152. 